\title{
Aerospace Systems and Technologies in Remote Sensing of the Earth
}

\author{
Boris I. Beliaev* \\ Research Institute of Applied Physical Problems \\ named after A.N. Sevchenko of the Belarusian State University \\ 7 Kurchatov, Minsk, 220108, Belarus
}

Received 03.02.2015, received in revised form 17.04.2015, accepted 07.08.2015

The long-term studies of natural formations in the optical wavelength range are described. The results of development and the creation of devices and ground-based, air-and spaceborne videospectral systems for study of the earth's surface by spectral methods, laboratory and flight equipment adjustment are considered.

Keywords: remote sensing, air- and spaceborne systems, equipment and systems adjustment, spectrometers, spectroradiometers.

\section{Авиакосмические системы и технологии В дистанционном зондировании Земли}

Б.И. Беляев

Институт прикладных физических проблем им. А.Н. Севченко

Белорусского государственного университета Республика Беларусь, 220108, Минск, ул. Курчатова, 7

\footnotetext{
Описываются многолетние исследования природных образований Земли в оптическом диапазоне длин волн. Рассматриваются результаты разработки и создания приборов и видеоспектральных систем наземного, авиачионного и космического базирования для изучения земной поверхности спектральными методами, лабораторные и полетные калибровки annapamypbl.

Ключевые слова: дистанционное зондирование, авиакосмические системы, калибровки приборов и систем, спектрометры, спектрорадиометры.
}

(c) Siberian Federal University. All rights reserved

* Corresponding author E-mail address: remsens@mail.ru 


\section{Введение}

Измерение, преобразование и анализ физических параметров световых полей объектов составляют основу дистанционных оптических методов изучения природных и искусственных образований.

Актуальность исследований в этой области определяется как необходимостью фундаментального изучения характеристик природных процессов, сред и объектов, так и решением конкретных прикладных задач.

Методы и системы дистанционного зондирования, использующие видеоспектральную информацию об объектах, находят все более широкое применение в научных исследованиях, в экономике (ГИС и производственно-хозяйственная инфраструктура), в сельском и лесном хозяйстве, экологии, в отслеживании и контроле чрезвычайных ситуаций (пожары, наводнения, природные и техногенные катастрофы) и т.д.

В данной работе описывается развитие основных элементов аэрокосмического мониторинга природных образований (методы, аппаратура, метрология, результаты обработки и представления данных), необходимых для эффективного решения как фундаментальных, так и прикладных задач.

\section{Спектрометры и спектрорадиометры}

\section{для дистанционной диагностики состояния сред и объектов}

В настоящее время в НИИПФП БГУ разработаны, созданы и широко используются в натурных экспериментах микропроцессорные спектрометрические модули (МС). Это серия дистанционного зондирования. В НИИПФП БГУ была разработана и изготовлена линейка многофункциональных приборов от МС-02 до MC-16 с комплектом специальных насадок и специальным программным обеспечением. Приборы (в комплекте с ПК) можно использовать для проведения измерений в лабораторных, наземных, полевых условиях, а также с борта летательных аппаратов [1,2].

Основные характеристики последних модификаций спектрорадиометров сведены в таблице.

Для расширения функциональных возможностей средств ДЗ3 и повышения точности диагностики состояния объектов в НИИПФП БГУ разработаны и созданы широкодиапазонные полевой спектрорадиометр ПСР-02 на диапазон 0,35-2,5 мкм со спектральным разрешением 2 нм в области 0,35-1,05 мкм и 10 нм для поддиапазона 1,05-2,5 мкм и переносной высокоточный спектрометр ПВС-02 (рис. 1) [3, 4].

С помощью созданных приборов проведен большой объем исследований по выявлению связей между оптическими характеристиками и физическими параметрами изучаемых объектов. Исследованы связи оптических характеристик внутренних водоемов с уровнем эвтрофирования, содержанием фитопланктона и минеральных взвесей. Разработаны методики определения уровня минерального питания сельскохозяйственных растений, оценки фитосанитарного состояния посевов картофеля, определения биомассы зерновых культур [2].

\section{Спектрально-энергетические наземные}

\section{и полетные калибровки приборов и систем}

Повышение требований к точности измерения радиометрических характеристик приемных датчиков оптоэлектронных приборов обусловлена усложнением и расширением круга за- 
Таблица. Основные характеристики спектрорадиометров

\begin{tabular}{|c|c|c|c|c|}
\hline Характеристики & MC-08 & MC-09 (10) & MC-11 (12) & MC-16 \\
\hline $\begin{array}{c}\text { Спектральный } \\
\text { диапазон, нм }\end{array}$ & 3501050 & 3401070 & 3501070 & 380950 \\
\hline $\begin{array}{c}\text { Спектральное } \\
\text { разрешение, нм }\end{array}$ & 2 & 1,2 & 2 & 2 \\
\hline $\begin{array}{c}\text { Шаг } \\
\text { дискретизации, } \\
\text { нм/канал }\end{array}$ & 0,7 & 0,35 & 0,2 & 0,1 \\
\hline Число каналов & 1024 & 2048 & 3648 & 3648 \\
\hline Детектор & $\begin{array}{c}\text { Фотодиодная } \\
\text { линейка }\end{array}$ & ПЗС линейка & ПЗС линейка & ПЗС линейка \\
\hline $\begin{array}{c}\text { Диспергирующий } \\
\text { элемент, } \\
\text { (штр/мм) }\end{array}$ & $\begin{array}{c}\text { Многосекционная } \\
\text { вогнутая решетка, } \\
(120) \\
\end{array}$ & $\begin{array}{c}\text { Многосекционная } \\
\text { вогнутая решетка, } \\
(120) \\
\end{array}$ & $\begin{array}{c}\text { Многосекционная } \\
\text { вогнутая решетка, } \\
(120) \\
\end{array}$ & $\begin{array}{c}\text { Вогнутая } \\
\text { голограммная } \\
\text { решетка, (315) } \\
\end{array}$ \\
\hline $\begin{array}{c}\text { Модель } \\
\text { компьютера }\end{array}$ & $\begin{array}{c}\text { SubNotebook ot } \\
\text { 386/486 IBM/ } \\
\text { Comp }\end{array}$ & $\begin{array}{c}\text { Partner E415L } \\
\text { (G320) }\end{array}$ & $\begin{array}{c}\text { Partner E415L } \\
\text { (G320) }\end{array}$ & $\begin{array}{c}\text { Смартфон } \\
\text { HUAWEI PG-U06 }\end{array}$ \\
\hline $\begin{array}{c}\text { Вес оптического } \\
\text { модуля, кг } \\
\end{array}$ & 4,0 & 3,7 & 3,2 & 1,9 \\
\hline
\end{tabular}
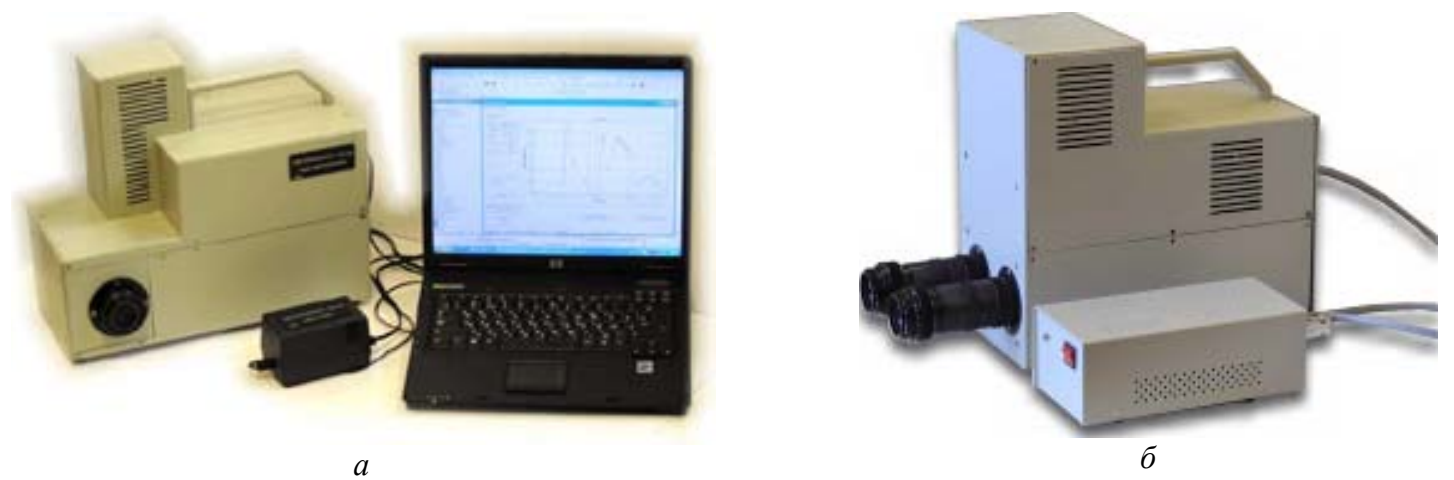

Рис. 1. Внешний вид широкодиапазонных спектрорадиометров: а - полевой спектрорадиометр ПСР-02; б - переносной высокоточный спектрометр ПВС-02

дач, решаемых методами дистанционного оптического зондирования, и необходимостью корректного сопоставления данных, получаемых различными приборами.

В НИИПФП им. А. Н. Севченко БГУ в 1989 г. создан метрологический комплекс «Камелия-М» в соответствии с поверочной схемой средств измерения спектральной плотности энергетической яркости (СПЭЯ) и модернизирован в 2003 г. Он предназначен для высокоточной калибровки различной спектрометрической и видеоспектральной аппаратуры в рабочем спектральном диапазоне от 0,35 до 2,5 мкм (рис. 3). Комплекс аккредитован в Госстандарте Республики Беларусь, регистрационный номер BY/112 02.5.0.0012 [5].

Основными операциями при калибровке аппаратуры на комплексе «Камелия-М» являются: определение рабочего спектрального диапазона; определение пороговых значений СПЭЯ и 

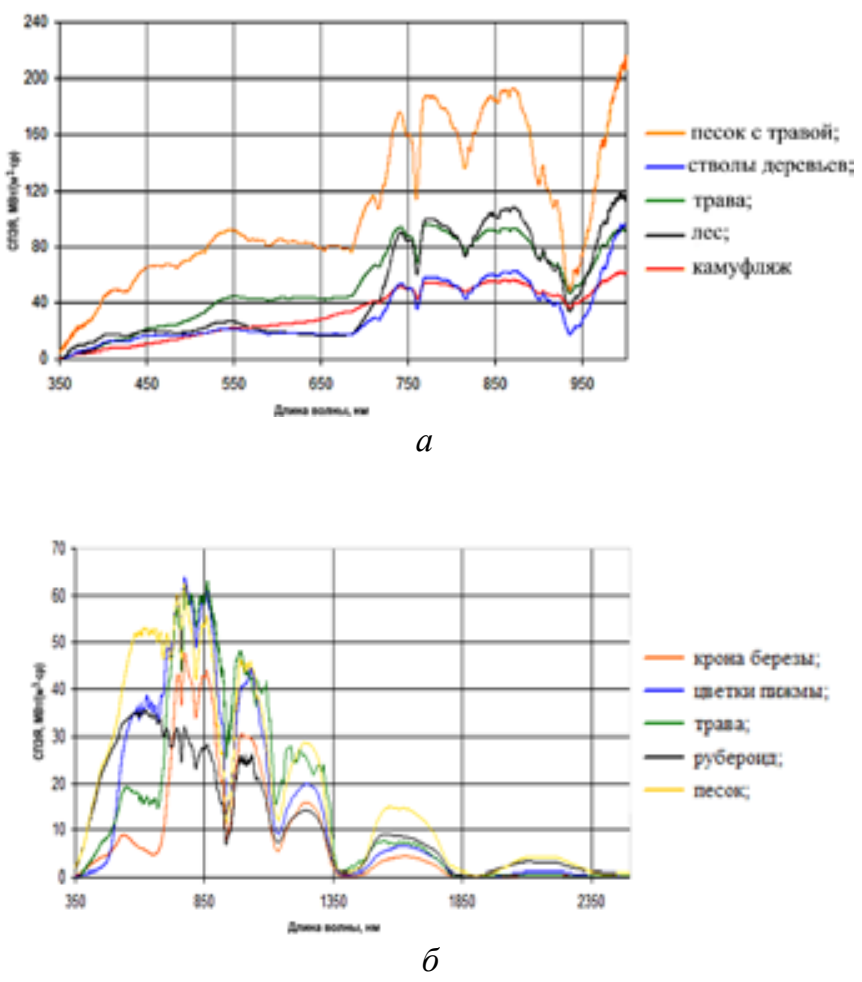

Рис. 2. Иллюстрация многообразия отражательных характеристик природных и искусственных объектов в диапазоне $0,35-1,0$ мкм (а) и $0,35-2,5$ мкм (б)



Рис. 3. Внешний вид метрологического комплекса «Камелия-М»

динамического диапазона; определение спектральной чувствительности по абсолютным значениям СПЭЯ.

После создания, наземной калибровки и запуска оптоэлектронных съемочных систем Д33, предназначенных для долговременного функционирования в условиях космического по- 
лета, встает важнейшая задача абсолютных радиометрических калибровок систем на борту космического носителя. Для осуществления полетных калибровок нами разработана методика многоуровневых измерений тестовых участков полигона БГУ «Западная Березина», включающая квазисинхронные измерения спектральных отражательных характеристик на трех уровнях - наземном, авиационном и космическом - и методики совместной тематической обработки спектров и изображений, позволяющие увеличить точность классификации подстилающих поверхностей за счет значительного увеличения количества спектральных каналов [2].

\section{Исследование характеристик природных образований с авиационных носителей}

Одной из систем авиационного мониторинга территорий РБ является авиационная система контроля АСК-ЧС, которая предназначена для определения масштабов и оценки последствий от ЧС различного уровня (рис. $4 a$ ). Основные научно-технические задачи, решаемые с помощью АСК-ЧС в интересах МЧС РБ: оперативное построение картосхем тепловых полей лесных, торфяных пожаров и других объектов в условиях сильной задымленности с координатной привязкой очагов горения, определение масштабов пожаров и последствий от них; определение масштабов утечек из нефте- и продуктопроводов, оценка их последствий; построение картосхем повреждений от ураганов; построение картосхем затопленных территорий и оценка последствий от наводнений. Система АСК-ЧС была установлена на самолете Ан-2 МЧС РБ и эффективно используется для решения задач предупреждения и ликвидации ЧС [6].

Еще одна авиационная спектрозональная система АВИС (рис. 4б) высокого пространственного и спектрального разрешения предназначена для регистрации спектрозональных, монохромных и тепловых изображений земной поверхности при авиационном мониторинге.

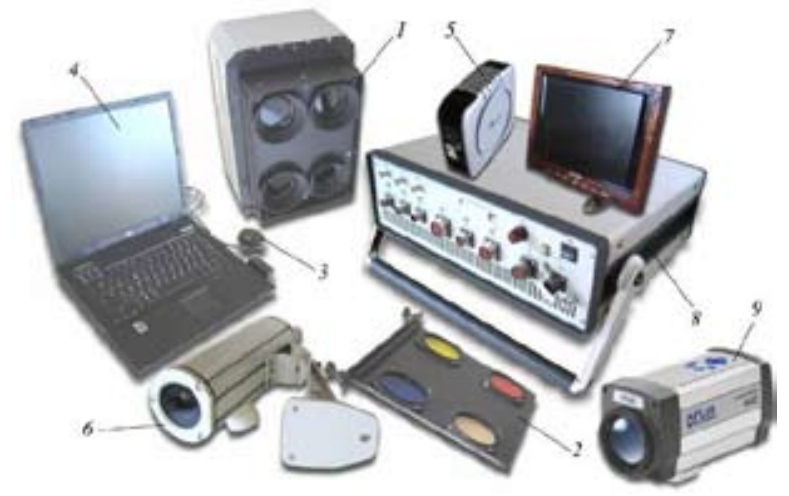

$a$

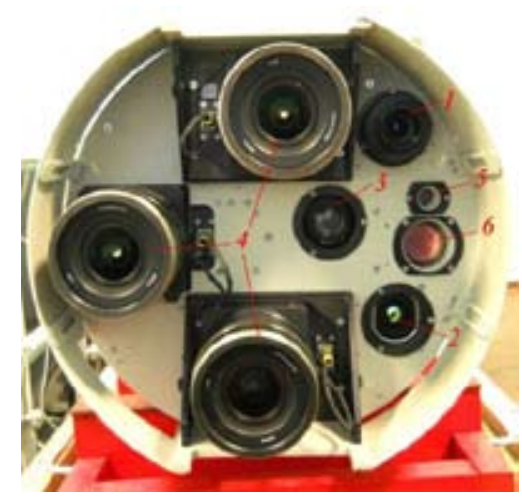

6

Рис. 4. Авиационные системы: $a$ - внешний вид блоков и датчиков АСК-ЧС (1- модуль зональной съемки; 2 - сменная кассета со светофильтрами; 3 - модуль координатной привязки; 4 - бортовой компьютер; 5 - модуль накопления видеоданных; 6 - модуль трассовой съемки; 7 - монитор пилота; 8 - модуль питания и коммутации; 9 - модуль инфракрасной съемки); 6 - внешний вид блока оптических датчиков АВИС (1 - объектив модуля съемочной камеры оператора; 2 - объектив модуля инфракрасной камеры; 3 - объектив модуля спектрорадиометра; 4 - три объектива съемочных камер модуля спектрозонального видеонаблюдения; 5 - объектив излучателя и 6 - объектив приемника модуля лазерного высотомера) 
АВИС предназначена для осуществления съемок объектов и территорий с авиационных носителей типа Ан-2, оборудованных специальным люком и гироплатформой с высот от 100 до 2500 м. АВИС обеспечивает: регистрацию ИК-изображений в диапазоне длин волн 7,5-13 мкм с числом элементов изображения $640 \times 480$; регистрацию спектрозональных изображений в диапазоне длин волн 400-900 нм с числом элементов изображения 33 Мпкс с пространственным разрешением 10 см с высоты 500 м; регистрацию спектров высокого разрешения в диапазоне 400-900 нм (МС14). Система АВИС эксплуатируется на самолетах ГП «Беллесавиа» МЧС РБ [7].

В ходе проведения съемок системами АСК-ЧС и АВИС получены тематические картосхемы с выделением основных классов лесных территорий для целого ряда лесничеств РБ. Результаты компьютерной классификации сравнивали с таксационными описаниями в базе данных ГИС «Лесные ресурсы». Корреляция результатов классификации и описаний ГИС «Лесные ресурсы» во всех случаях достаточно высокая и составляет 75-95 \% [2].

\section{Космические видеоспектральные системы}

Космические исследования подстилающих поверхностей проводились нашими приборами - малогабаритными скоростными спектрометрами серии МСC-2 - с борта ОНС «Салют-4» «Салют-6» «Салют-7». С 1988 г. на борту орбитальной станции «Мир» функционировала микропроцессорная система регистрации, накопления и обработки видеоспектральной информации «Гемма 2-видео», разработанная и созданная в НИИПФП БГУ. С системой «Гемма 2-видео» была проведена обширная серия космических экспериментов по геоэкологическим исследованиям спектральных отражательных характеристик различных типов подстилающих поверхностей и атмосферы Земли [2].

К настоящему времени в НИИПФП БГУ совместно с Институтом географии РАН по заказу ОАО «РКК «Энергия» им. С.П. Королева» разработана и изготовлена фотоспектральная система ФСС (рис. $5 a$ ), предназначенная для регистрации спектров отраженного излучения подстилающих поверхностей в диапазоне длин волн 350-1050 нм, однозначно «привязанных» к цветным изображениям высокого пространственного разрешения с борта российского сегмента МКС в космическом эксперименте «Ураган» [8] - «Экспериментальная отработка наземно-космической системы мониторинга и прогноза развития природных и техногенных катастроф». Цель научной программы «Ураган»- выработка требований к наземно-космической системе предупреждения катастроф. С августа 2010 г. всеми экспедициями на МКС проводятся регулярные съемки аппаратурой ФСС спектров и изображений различных участков земной поверхности при различных условиях освещения и наблюдения. Получен большой объем информации по многим регионам земного шара. Ведется обработка данных $[9,10]$.

Логическим развитием системы ФСС явилась разработанная и созданная в НИИПФП БГУ видеоспектральная система ВСС (рис. 5б), также предназначенная для проведения измерений характеристик отраженного излучения подстилающих поверхностей в диапазоне длин волн от 400 до 950 нм на служебном модуле российского сегмента МКС при выполнении мониторинга земной поверхности в ходе проведения научно-прикладных исследований в космическом эксперименте «Ураган» [11]. В результате применения разработанной нами методики декомпозиции и последующей интерполяции спектров, применяемой к совокупности данных, полу- 


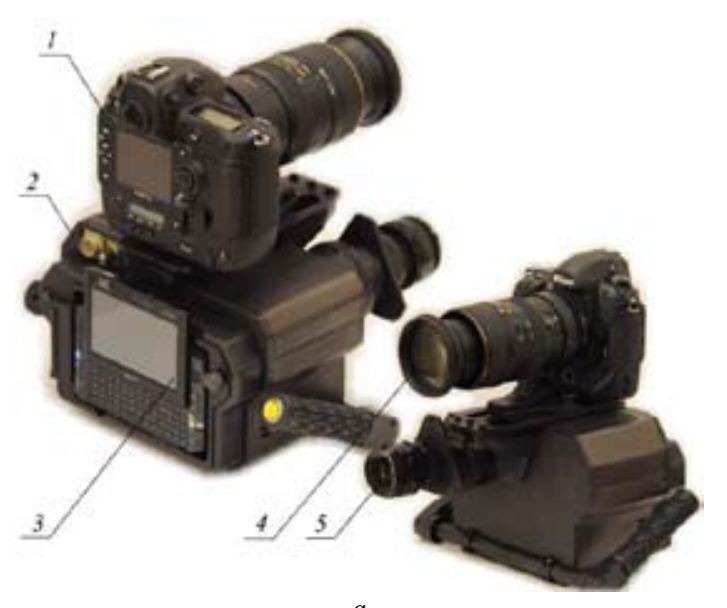

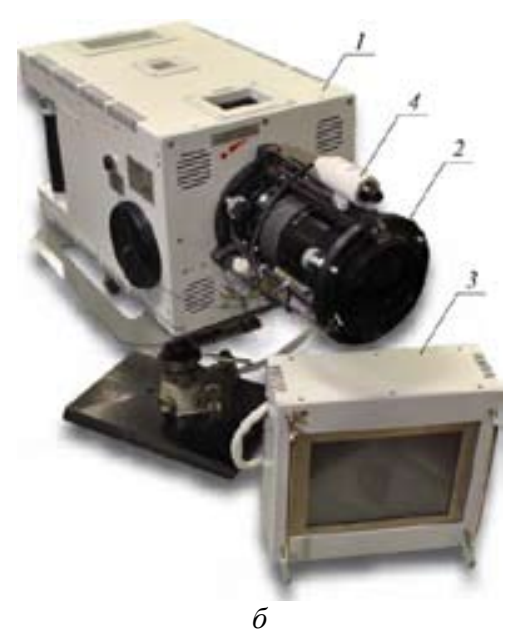

Рис. 5. Внешний вид космических видеоспектральных систем: а - ФСС (1 - модуль регистрации изображений (МРИ); 2 - модуль спектрометрический (МС); 3 - планшетный компьютер модуля электроники; 4 - объектив МРИ; 5 - объектив МС); б - ВСС (1 - базовый блок; 2 - блок объектива; 3 - блок монитора; 4 - камера видеосопровождения)

чаемых ВСС, последняя по информативности будет близка к видеоспектрометрам, и это дает возможность применять методы классификации, основанные на совместном использовании спектральной, пространственной (текстурной) и угловой информации. Система ВСС успешно прошла все испытания и в октябре 2014 г. доставлена на МКС.

\section{Некоторые результаты исследований Земли из космоса}

Солнечный спектр является непрерывным в крайне широком диапазоне частот - от низкочастотного радиоволнового до сверхвысокочастотного рентгеновского и гамма-излучения. В спектре солнечного излучения, достигающего поверхности Земли, присутствуют линии Фраунгофера (поглощение химическими элементами в атмосфере Солнца в диапазоне 390-520 нм), а также теллурические линии и полосы, обусловленные поглощением компонентами атмосферы - преимущественно озоном, парами воды и молекулярным кислородом (рис. $6 a$ ). На рис. $6 б$ показана геометрическая схема измерений спектров рассеяния излучения атмосферой при спектрометрировании с поверхности Земли при различных углах визирования по отношению к зениту и из космоса.

Исследования оптических характеристик фонов Земли (системы «подстилающая поверхность - атмосфера») проводили с целью систематизации данных, составления каталогов и атласов спектроэнергетических характеристик основных классов природных фонов и формирования модели фонов Земли как планеты в целом. На рис. 7 приведены некоторые результаты геофизических экспериментов по исследованию яркостей природных фонов и их зависимостей от зенитного угла Солнца $[2,12]$.

Было установлено, что яркости излучения, отраженного от поверхности воды, зависят не только от зенитного угла Солнца, но для акваторий океана зависят также от атмосферных аэрозольной и молекулярной индикатрис рассеяния. Чем короче длина волны отраженного излучения, тем меньше яркость зеркального отражения от поверхности воды. В ходе иссле-

$$
-696-
$$



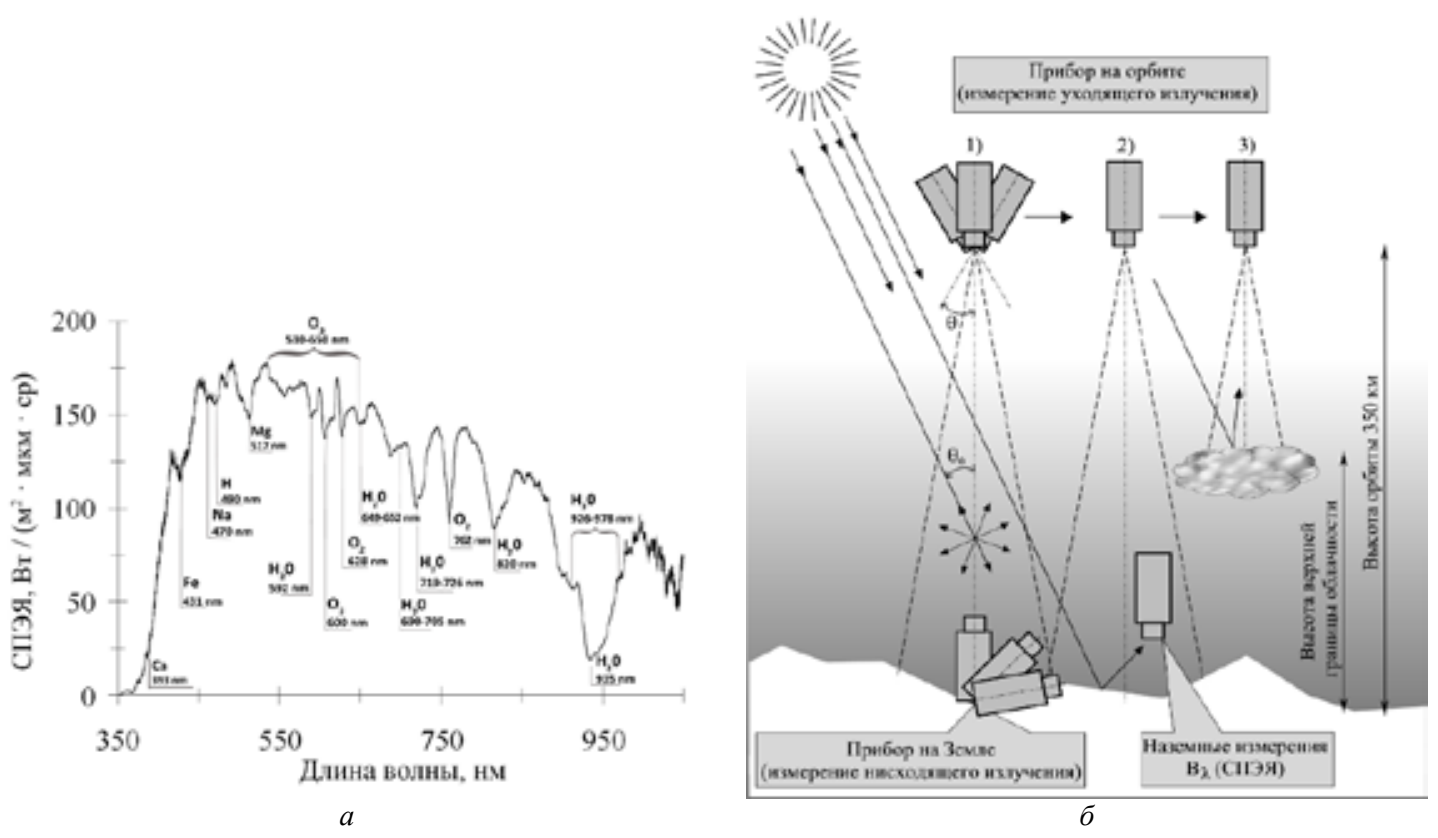

Рис. 6. А - Зарегистрированный прибором МС-12 спектр отражения с обозначенными фраунгоферовыми и теллурическими линиями; б - схема геометрии измерений при Д33: 1 - уходящая и пропущенная солнечная радиация; 2 - СПЭЯ восходящего излучения при космических и наземных измерениях; 3 - СПЭЯ облачности

дований были определены оптимальные условия наблюдения цветовых различий и спектральных контрастов, благоприятных для обнаружения биопродуктивных районов океана. Найдены статистические связи выходящего из воды излучения с содержанием пигментов фитопланктона.

На основе анализа полученных данных было показано, что по спектральной яркости отраженного Землей излучения можно проводить физико-географическое районирование территорий, т.е. различать физико-географические зоны и физико-географические провинции. Даже такому мелкому географическому делению, как провинция, соответствует свой среднестатистический спектральный образ [2].

Исследования светового ореола Земли проводили при спектрофотометрировании дневного горизонта планеты методом пространственного сканирования горизонта Земли оптической осью аппаратуры под разными углами.

Были определены толщины оптического слоя атмосферы в различных участках спектра. Так, для красной области (0,62-0,72 мкм) она равна (27 \pm 4$)$ км, а для синей - (36 \pm 4$)$ км, что связано с особенностями рассеяния света в атмосфере. Уверенно обнаруживаются при этом оптические неоднородности на высотах 17-20 км - это аэрозольный слой Юнге.

Оптико-физические характеристики серебристых облаков были определены в результате впервые полученных уникальных данных инструментальных измерений из космоса. Серебристые облака - это самые высотные облака в атмосфере Земли. Они образуются в районе высокоширотной летней мезопаузы на высотах 80-85 км. Имеют очень малую оптическую толщину. На основании наших исследований удалось установить, что серебристые облака -

$$
-697-
$$



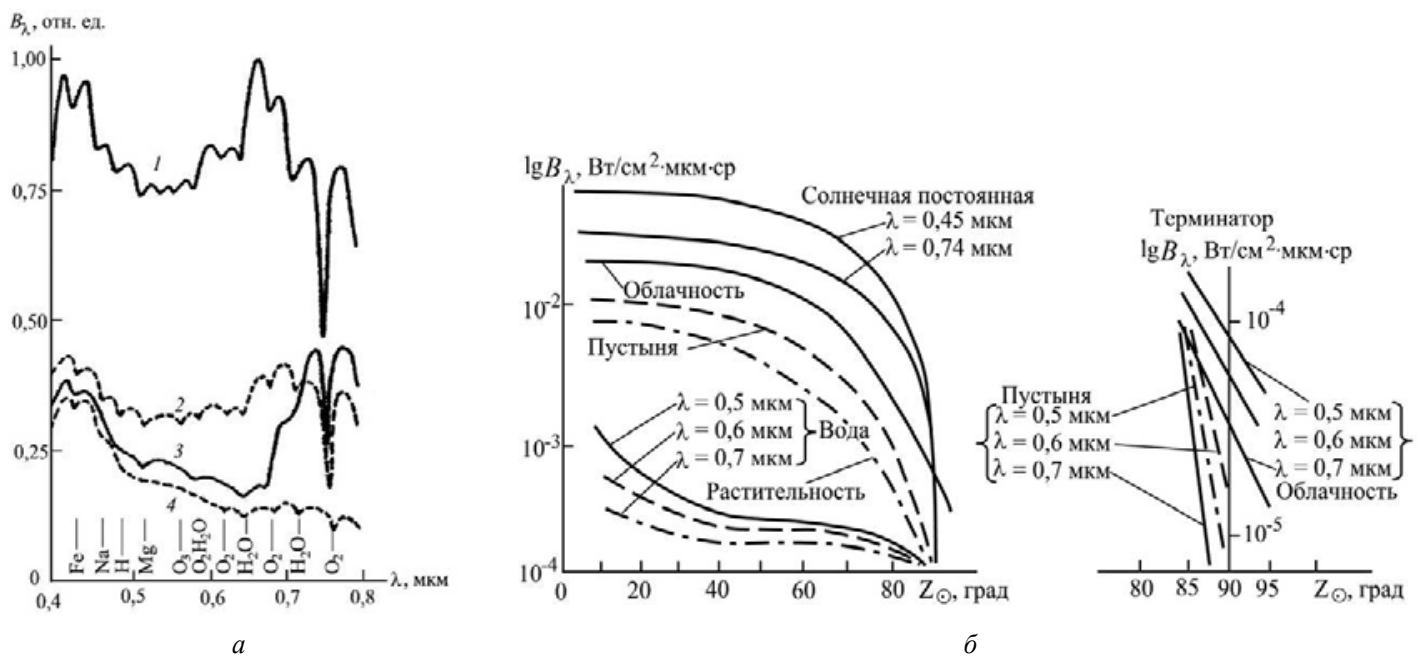

Рис. 7. Оптические характеристики фонов Земли: $a$ - спектральные яркости фонов при одном $Z_{\odot}$ : 1 - облачность, 2 - пустыня, 3 - растительность, 4 - вода; $\sigma$ - зависимость спектральной яркости $B_{\lambda}$ от зенитного угла Солнца $\mathrm{Z}_{\odot}$ для основных классов природных фонов

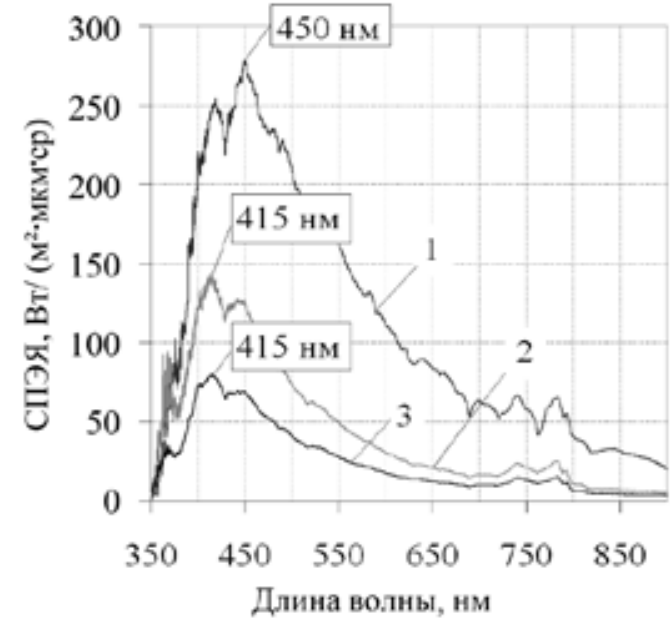

$a$

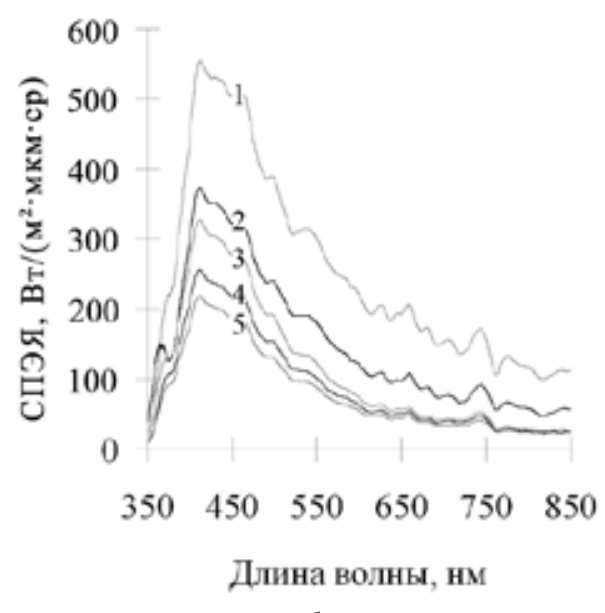

б

Рис. 8. $A$ - Экспериментальные спектры восходящего излучения, измеренные из космоса: 1 - облачности; 2 - водной поверхности; 3 - растительности; $\sigma$ - экспериментальные спектры восходящего излучения, измеренные из космоса над водными поверхностями при различных зенитных углах Солнца: $1-22,3$; $2-31,1 ; 3-58,1 ; 4-63,5 ; 5-67,9$

это полидисперсная среда, состоящая из ансамбля идентичных сферических частиц, где распределение частиц по размерам выражается законом Юнге $\left(r_{\min }=0,025\right.$ мкм - минимальный и $r_{\max }=1,9$ мкм - максимальный радиусы частиц в ансамбле). Концентрация частиц в облаке составляет $6 \mathrm{~cm}^{-3}[2]$.

Спектральные распределения яркости излучения Земли из космоса. На рис. 8 а приведены экспериментальные спектры восходящего излучения, измеренные ФСС из космоса, при углах наблюдения, близких к надиру (для диапазона 350-700 нм). 
Из рис. $8 a$ и $8 б$ и других имеющихся в нашем распоряжении измерений из космоса видно, что максимум уходящего излучения смещен в синюю область по отношению к максимуму солнечного излучения ( $\lambda_{\max }=460-470$ нм) на 50-60 нм для слабоотражающих в «синей» области поверхностей (водных и растительных) и находится на длинах волн $\lambda_{\max }=410-415$ нм. Среднестатистическое значение «голубого» смещения для безоблачной атмосферы составляет 55 нм.

Положение максимума яркости над водными поверхностями в чистой атмосфере (рис. 9б) при изменении зенитных углов Солнца от 20 до $70^{\circ}$ остаётся практически постоянным в окрестности 410 - 415 нм, что свидетельствует о преобладающем в этом случае вкладе молекулярного рассеяния света в атмосфере, обладающего практически круговой индикатрисой рассеяния.

\section{Заключение}

В статье представлены результаты разработок оптико-электронных систем дистанционной спектрометрии, предназначенные для исследований различных природных и искусственных образований и сред в видимом и ближнем ИК-диапазонах спектра в наземных условиях с авиационных носителей и из космоса.

Приведены некоторые результаты комплексных исследований оптико-спектральных характеристик природных образований с помощью созданных приборов и систем дистанционного зондирования Земли.

Представленные в статье оптико-спектральные характеристики природных образований, полученные с помощью созданных приборов и систем ДЗ3, использовались для диагностики состояния различных сред и объектов. Все описанные приборы и комплексы прошли всесторонние испытания и нашли применение в различных организациях и ведомствах Беларуси, России и странах ближнего зарубежья.

\section{Список литературы}

[1] Беляев Б.И., Сосенко В.А. // Журнал прикладной спектроскопии. 1997. Т. 64. № 6. С. $827-$ 833.

[2] Беляев Б.И., Катковский Л.В. Оптическое дистанционное зондирование. Минск: БГУ, 2006. $455 \mathrm{c}$.

[3] Беляев Б.И., Беляев Ю.В., Нестерович Э.И. и др. // Приборы и техника эксперимента. 2010. № 3. С. 127-132.

[4] Беляев Б.И., Беляев Ю.В., Цикман И.М. // Журнал прикладной спектроскопии. 2010. Т. 77. № 5. С. 774-780.

[5] Беляев Б.И., Беляев Ю.В., Залетный В.М. и др. Приборы для научных исследований: Каталог приборов, комплексов, установок, разработанных по ГКНТ «Приборы для научных исследований». Минск, 2006. С. 13-16.

[6] Катковский Л.В., Хвалей С.В., Шукайло В.Г., Сизиков А.С. // Чрезвычайные ситуации: предупреждение и ликвидация. 2013. № 2 (34). С. 66-80.

[7] Хвалей С.В., Беляев Б.И., Беляев Ю.В. и др. // Современные проблемы дистанционного зондирования Земли из космоса: Тезисы докладов 9-й открытой Всероссийской конференции. M., 2011.

$$
-699-
$$


[8] Беляев Б.И., Катковский Л.В., Сосенко В.А. // Наука и инновации. 2013. № 5 (123). С. 1518.

[9] Беляев Б.И., Беляев М.Ю., Десинов Л.В. и др. // Журнал прикладной спектроскопии. 2012. Т. 79. № 4. С. 669-675.

[10] Беляев Б.И., Беляев М.Ю., Десинов Л.В. и др. // Исследование Земли из космоса. 2014. № 6. С. 27-39.

[11] Беляев Б.И., Беляев М.Ю., Гусев В.Ф. и др. // Материалы Шестого Белорусского космического конгресса. 2014. Т. 1. С. 211-214.

[12] Беляев Б.И. // Информатика. 2007. № 3. С. 103-113. 